\title{
VIOLÊNCIA, PRECONCEITO E EXCLUSÃO SOCIAL NA LITERATURA BRASILEIRA DO SÉCULO XX
}

\author{
Lizandro Carlos Calegari
}

Resumo: Este trabalho visa a refletir sobre a violência, o preconceito e a exclusão social a partir de algumas obras específicas da literatura brasileira produzidas no século XX. Particularmente, deu-se destaque a autores em cujas obras há a representação de grupos marginalizados que sofrem com a violência e a discriminação em razão do status social, do preconceito racial e sexual. A partir da referência a textos de autores como Graciliano Ramos, Clarice Lispector, Caio Fernando Abreu, Luiz Silva e Rubem Fonseca, chegou-se à conclusão de que a violência, no Brasil, é algo histórico e socialmente legitimado, garantindo os processos de discriminação e de exclusão social, que se fazem representar na literatura.

Palavras-chave: Violência; preconceito; exclusão social; autoritarismo; literatura brasileira.

Abstract: This paper aims at reflecting on the violence, the prejudice, and the social exclusion departing from some specific works from Brazilian literature produced in the $20^{\text {th }}$ century. It was given particular attention to those authors whose books and short stories represent marginalized groups that suffer from violence and discrimination based on social status, racial, and sexual prejudice. Works by Graciliano Ramos, Clarice Lispector, Caio Fernando Abreu, Luiz Silva, and Rubem Fonseca were referred, and it could be concluded that violence in Brazil is something historically and socially legitimated, ensuring processes of discrimination and social exclusion, which are depicted in literature.

Keywords: Violence; prejudice; social exclusion; authoritarianism; Brazilian literature.

\footnotetext{
${ }^{1}$ Doutor em Letras pela UFSM. Professor de Língua e Literatura na mesma instituição. E-mail: lizandro.calegari@yahoo.com.br
} 
Violência, preconceito e exclusão social são temas recorrentes na literatura brasileira. Vários autores têm denunciado, por meio de suas obras, as injustiças que determinadas parcelas colocadas à margem da sociedade e da história têm sofrido em virtude do abuso de poder praticado por grupos específicos. Trata-se de cenas que definem uma sociedade autoritária que se edifica pautada em situações que envolvem assassinatos, chacinas, estupros, sequestros, torturas e discriminações em virtude das posições sociais, da cor, da orientação sexual e dos credos assumidos pelos indivíduos. Assim, embora se alegue que o Brasil se constitua numa democracia, em que os opostos convivem pacificamente, o que se verifica, em verdade, é uma hierarquização das estruturas do poder.

Essa hierarquia de poder, que cria as velhas noções de centro e de periferia, tem moldado o Brasil desde os primórdios de seu processo colonizatório, forjando situações e, com elas, ideologias que visam a atender aos interesses de grupos que têm, em suas mãos, as rédeas para o controle do país. Interessa a essa parcela de mandatários não apenas esse domínio e essa administração severa da sociedade, mas, sobretudo, a ocultação da violência que ela mesma incita. Se não há crimes, não há culpados; se não há culpados, não há punição, pena ou castigo. Desresponsabilizam-se os algozes pelas suas ações brutais e desumanas. Trata-se, pois, de uma logística que objetiva, em última instância, apagar da memória de um povo um passado de violências com o intuito de manutenção de uma ordem construída e instituída historicamente.

$\mathrm{Na}$ literatura brasileira, essa questão associada ao apagamento do passado como forma de controle e de dominação pode ser analisada de diversos ângulos. Numa perspectiva diacrônica, convém chamar a atenção para a constituição do cânone que, como bem observou Roberto Reis (1992, p. 73), exclui segmentos culturalmente marginalizados e politicamente reprimidos como mulheres, etnias não-brancas e homossexuais, dentre muitos outros. Se a esses grupos não são concedidos voz nem espaço, não terão suas ideias debatidas nem confrontadas, consequentemente, seu passado de violência permanecerá desconhecido. Além disso, atualmente, não se pode ignorar o poder da indústria cultural na definição de gostos e de 
padrões de leituras alienantes, que contribuem para 0 apagamento do passado e que impedem que os leitores se adentrem nos problemas sociais emergentes à sua volta (cf. ADORNO; HORKHEIMER, 1985).

Partindo-se dessas considerações, é plausível afirmar que a literatura brasileira pode ser pensada a partir de sua relação com a violência e com os inúmeros processos de exclusão a que diversos grupos sociais têm sido submetidos historicamente. Uma estrutura social que convive com uma ordem de valores autoritários não se desfaz por meros rearranjos institucionais. É preciso políticas públicas sérias que oportunizem espaço para o debate consistente sobre problemas sociais fundamentais, mas é preciso também que todas as camadas se conscientizem dos malogros históricos de que têm sido vítimas. A literatura, pelo que se tem averiguado nas últimas décadas, tem contribuído para o desocultamento das relações de poder as quais têm motivado a violência, patrocinado a exclusão e gerado ideologias discriminatórias.

Diferentemente do que ocorrera até os últimos decênios do século XIX, a literatura brasileira, a partir do século XX, em especial com os modernistas, procurou renovar o seu olhar acerca da realidade nacional, desenvolvendo sobre ela um constante enfoque crítico. Nessa esteira de renovações temáticas e formais, avultam autores e obras que denunciam, por meio de situações e personagens, a violência arbitrária que significativa parcela da população brasileira tem sofrido secularmente. Assim, surgem nomes que desfazem aquele olhar idealizante lançado sobre o país, deixando transparecer, em seus livros, as mazelas, os atrasos, os dilemas históricos e sociais assegurados por ideologias autoritárias.

Nesse sentido, provavelmente, uma das passagens mais célebres de Vidas secas (1938), de Graciliano Ramos, é aquela em que Fabiano, depois de ter sido covardemente agredido por um soldado amarelo e de ter ficado na cadeia por uma noite, casualmente, reencontra-se, um ano depois, com o seu agressor perdido em meio à caatinga do sertão nordestino. Portando um facão, o protagonista poderia ter vingado a sova recebida do policial tempos antes, desferindo-lhe um golpe certeiro e fatal; entretanto, hesita e desiste do crime: 
Afastou-se, inquieto. Vendo-o acanalhado e ordeiro, o soldado ganhou coragem, avançou, pisou firme, perguntou o caminho. E Fabiano tirou o chapéu de couro.

- Governo é governo.

Tirou o chapéu de couro, curvou-se e ensinou o caminho ao soldado amarelo. (RAMOS, 1971, p. 152)

Nesse fragmento, Fabiano curva-se frente à autoridade e, nesse gesto, deixa transparecer a sua fragilidade e submissão a alguém que ele julga ser superior porque é representante do Estado e da lei. No modo de pensar do vaqueiro, o simples fato de o soldado representar o governo, por si só, justificaria $o$ ato violento e covarde da autoridade e explicaria a sua aceitação sem qualquer questionamento. Aqui, deve-se conceber Fabiano como um típico representante da sociedade civil, acuada e indefesa, que se deixa humilhar por qualquer um dotado de algum grau de poder, qualquer que seja. Ao afirmar que "Governo é governo", o protagonista deixa claro que, na sua compreensão da realidade, todas as atitudes e decisões do poder são inquestionáveis e autossustentáveis. É a suposta ideia de que a lei, por ser determinada pelo Estado, é legítima em si mesma.

Essa ordem tautológica de interpretar o poder - "Governo é governo" remete a um importante ensaio de Walter Benjamin intitulado "Crítica da violência, crítica do poder", publicado em 1921 (BENJAMIN, 1986). O argumento principal desse estudo radica em torno da ideia de que a lei, em sua essência, é contaminada pela violência que a funda e permanece nela representada pela coerção estatal. Com isso, a lei, no exercício sobre a vida e a morte, reafirma-se sobre si mesma. Forma-se, desse modo, um espaço vazio, que, para cobri-lo, a violência fundante da lei determina algo de podre na lei mesma que, de certa maneira, sempre se revela. A lei, portanto, nasce condenada à decadência interna, uma vez que o preceito legal é desprovido de justificação ou legitimação, pois o raciocínio jurídico é sustentado por uma dimensão de força e de violência que assume o vazio do fundamento que falta.

Ainda de acordo com o filósofo alemão, o poder-violência é fundador e mantenedor do direito, da lei e do Estado. A esse tipo de poder-violência que consegue, de diferentes formas, aprisionar o ser humano em um destino 
cíclico de condenação, de culpa e de expiação Benjamin denomina de mítico. Ao afirmar que o direito tem sua origem no mito, o autor quer dizer que ele se funda em um poder misterioso que aprisiona o homem na ilusão. Trata-se de uma força demoníaca que tem como propósito a redução da vida em uma mera vida, a fim de melhor controlá-la. Em suma, fundado em um movimento cíclico, todo poder-violência ou instaura ou conserva o direito e a lei. A partir disso, o autor investiga essas forças míticas, que, do seu ponto de vista, fundam o direito e a lei calcados na violência, uma violência instauradora e mantenedora do poder e da ordem.

O caso de Fabiano é exemplar para se entender a lógica interna de funcionamento das ideologias autoritárias que condenam os seres humanos à passividade frente ao poder, às leis e ao Estado. Como consequência, cria-se um ciclo reificado de pensamento que aceita como legítimo aqueles sujeitos, comportamentos e situações que atendam exclusivamente aos interesses do Estado. Trata-se da disseminação da ideologia dominante, buscando, através da submissão da ordem instituída, fazer ou produzir um homem projetado segundo a lógica da identidade e do modelo mecanicista da natureza. Não interessa a esse padrão de conhecimento investir em um modo de pensar assentado numa lógica da diferença e, por isso, tudo o que é não-idêntico e constitui o outro da razão deve ser colocado fora de um determinado esquema de pensamento já que é suspeito de irracionalidade.

É o que tem acontecido, particularmente, com as minorias sexuais e étnico-raciais. A discriminação sexual e a racial têm sido denunciadas em obras de alguns escritores como forma de reação ao sistema patriarcal o qual concebe o homem branco e heterossexual como detentor da verdade. E, se existe uma verdade, é porque existe a voz de uma autoridade. Trata-se de uma autoridade que cria o seu centro e, em torno dele, estão aqueles indivíduos que constituem o outro da razão e que guardam um passado de violência, de preconceito e de exclusão social. A propósito, uma autora que, em suas obras, denunciou esse sistema patriarcal injusto e machista foi Clarice Lispector.

Em Laços de família (1960), um dos contos que aborda a consciência da discriminação enfrentada pelas mulheres na sociedade patriarcal intitulase "Preciosidade" (LISPECTOR, 1998). O texto narra a história de uma Revista Eletrônica Literatura e Autoritarismo: Narrativa Testemunhal e Relações Históricas - ISSN 1679-849X |9| http://cascavel.ufsm.br/revistas/ojs-2.2.2/index.php/LA/index 
adolescente de quinze anos impotente frente ao olhar masculino. Pela manhã, a sua rotina consiste em pegar um ônibus para ir à escola. Nesse trajeto, ela se sente vigiada por todos: "também de rapazes tinha medo, medo também de meninos. Medo que Ihe 'dissessem alguma coisa', que a olhassem muito" (Ibid., p. 83). No espaço doméstico, ela se sente protegida, ao passo que, nas ruas, encontra-se desamparada: "Na casa vazia, sozinha com a empregada, já não andava como um soldado, já não precisava tomar cuidado. Mas sentia falta da batalha das ruas" (Ibid., p. 86). Nesse sentido, ela reconhece que seu corpo é a sua ruína, motivo de sua humilhação.

Certo dia, pela manhã, cumprindo o mesmo ritual de sempre, antes que o escuro da madrugada cedesse lugar à luz do dia, avista dois rapazes que, vindo em sua direção, tocam em seu corpo:

O que se seguiu foram quatro mãos difíceis, foram quatro mãos que não sabiam o que queriam, quatro mãos erradas de quem não tinha a vocação, quatro mãos que a tocaram tão inesperadamente que ela fez a coisa mais certa que poderia ter feito no mundo dos movimentos: ficou paralisada. Eles, cujo papel predeterminado era apenas o de passar junto do escuro de seu medo, e então o primeiro dos sete mistérios cairia; eles que representariam apenas o horizonte de um só passo aproximado, eles não compreenderam a função que tinham e, com a individualidade dos que têm medo, haviam atacado. Foi menos de uma fração de segundo na rua tranquila. Numa fração de segundo a tocaram como se a eles coubessem todos os sete mistérios. Que ela conservou todos, e mais larva se tornou, e mais sete anos de atraso. (lbid., p. 90)

Trata-se de um dos poucos contos de Clarice, da obra em questão, em que se observa a interferência física direta de homens sobre uma figura feminina. Assim, pode-se falar, nesse particular, da violência contra a mulher na medida em que a protagonista tem a sua intimidade invadida num contexto que não the oferece nenhum tipo de proteção ${ }^{2}$. O fato de ela ter ficado inerte frente à ação dos supostos agressores traduz o comportamento das mulheres em geral quando violentadas dentro de uma sociedade patriarcal. No texto,

\footnotetext{
${ }^{2}$ É importante assinalar, aqui, que nem toda manifestação de desejo não requisitada pelo outro constitui-se em violência. Em relação ao conto em apreciação, está-se considerando o comportamento da protagonista e o modo como ela concebe, consciente ou inconscientemente, a sociedade à sua volta.
}

|10| Revista Eletrônica Literatura e Autoritarismo, oo 27 - janeiro a junho de 2016 - ISSN 1679-849X http://cascavel.ufsm.br/revistas/ojs-2.2.2/index.php/LA/index 
tem-se conhecimento da perplexidade da vítima, enquanto que os dois sujeitos fogem ilesos pelos seus atos. A questão, aqui, conforme Lucia Ozana Zolin (2003), é que o patriarcalismo tornou-se uma realidade tão bem sucedida, tão arraigada no inconsciente coletivo que, para muitos, "é impossível pensar as relações humanas de modo que o macho não domine de direito e de fato" (p. 43).

Heleieth Saffioti (2004), ao discutir as relações entre gênero, patriarcado e violência, postula que as mulheres são treinadas para sentir culpa dos abusos, das agressões e da discriminação sofrida (p. 23). Muitas vezes, a violência infligida a elas é motivada não apenas por homens, mas pelas próprias atitudes das mulheres, atitudes essas que, em última instância, culminam num processo de exclusão. No mesmo livro de Lispector, o conto "A menor mulher do mundo" coloca em pauta essa questão.

Nesse texto, as mulheres demonstram uma atitude de rejeição ou de bizarra ternura por Pequena Flor, a menor mulher do mundo, membro de uma sociedade primitiva. Ela mora numa árvore e é caçada como se caça um animal: com redes. Ela cozinha; o homem caça. Ao se coçar diante de um explorador "onde uma pessoa não se coça" (LISPECTOR, 1998, p. 70), ela deixa explícito que desconhece as normas de civilização. É essa mulher de 45 centímetros, que mora no topo de uma árvore, "escura como um macaco" (Ibid., p. 72), que será vista, num jornal de domingo, pelas mulheres urbanas e civilizadas que residem em apartamentos. Como se observa, trata-se de dois tipos de mulheres, uma primitiva e outra civilizada, que vivem numa mesma época, mas é como se vivessem separadas há séculos. O texto problematiza, assim, a desunião e a exclusão entre as mulheres.

Se a violência e a exclusão acometem às mulheres e, por extensão, os personagens femininos, o mesmo pode ser dito em relação aos sujeitos homossexuais ${ }^{3}$. Historicamente discriminados, têm constituído um grupo que se depara, nas diversas instâncias sociais, com o preconceito e a humilhação. Dentro de uma sociedade patriarcal, de herança colonial, machista e homofóbica, ser homossexual é desafiar o establishment, o qual é sustentado

\footnotetext{
3 Talvez a melhor expressão para se referir a essas pessoas seja "sujeitos de desejos homoeróticos"; porém, aqui, usou-se o vocábulo "homossexuais", embora se tenha consciência de que não é o termo mais apropriado.
} 
por diferentes instituições como a família, o exército e a igreja, só para citar algumas, que se unem para defender seus privilégios e garantir uma certa ordem. Embora, já no final do século XIX, algumas obras tenham tocado no assunto, as relações homoerótica, enquanto tema, ganharam vulto, no Brasil, nas últimas décadas do século $X X$, o que demonstra o elevado grau de conservadorismo no país. A questão sempre tem sido polêmica, e muitos escritores - talvez por receio de serem rechaçados - têm escondido a sua condição homossexual (cf. TREVISAN, 2007, p. 249-273) ${ }^{4}$.

Nos anos 1980, Caio Fernando Abreu é um dos autores que dedica atenção ao tema do preconceito e da homofobia em contos como "Aqueles dois" e "Terça-feira gorda". Convém observar que esses textos, ambos publicados em Morangos mofados (1982), foram escritos durante a Ditadura Militar (1964-1985) e, embora os jovens estivessem vivendo o clima da contracultura que ecoava dos movimentos de maio de 1968, a censura e seus mecanismos de repressão ainda falavam mais alto. Existem poucos estudos acerca das relações entre regimes autoritários e temas ligados ao homossexualismo. Contudo, à época, tal categoria era duplamente censurada: “por atentar à moral' e/ou simplesmente por fazer alusão ao homossexualismo em si, ainda que de forma jocosa" (BERG, 2002, p. 18-19).

Apesar de a violência contra os homossexuais ser algo intrínseco à vida brasileira, durante a ditadura, ela se tornou mais explícita e forte, pois a homossexualidade era considerada como um problema de ordem médicocientífica, enquadrando-se como "ofensa ao decoro público" (Ibid., p. 102). Além desse tema, qualquer comportamento que comunicasse intenções lascivas e obscenas era repreendido. O conto "Aqueles dois", aliás, é exemplar na representação da homofobia dentro de uma sociedade conservadora e patriarcal. Narra a amizade entre dois jovens, Raul e Saul, que se conheceram numa firma, no expediente de trabalho. Depois de um tempo, são demitidos pelo fato de serem acusados de homossexuais:

Fazia muito calor. Suarento, o chefe foi direto ao assunto: tinha recebido algumas cartas anônimas. Recusou-se a

\footnotetext{
${ }^{4}$ Nessas páginas intituladas "Essas histórias de amor maldito", o autor percorre nomes e obras da literatura brasileira que se dedicaram ao tema em questão.

|12| Revista Eletrônica Literatura e Autoritarismo, № 27 - janeiro a junho de 2016 - ISSN 1679-849X http://cascavel.ufsm.br/revistas/ojs-2.2.2/index.php/LA/index
} 
mostrá-las. Pálidos, os dois ouviram expressões como "relação anormal e ostensiva", "desavergonhada aberração", "comportamento doentio", "psicologia deformada", sempre assinadas por Um Atento Guardião da Moral. Saul baixou os olhos desmaiados, mas Raul levantou-se de um salto. Parecia muito alto quando, com uma das mãos apoiadas no ombro do amigo e a outra erguendo-se atrevida no ar, conseguiu ainda dizer a palavra nunca, antes que o chefe, depois de coisas como a-reputação-de-nossa-firma ou tenho-que-zelar-pelamoral-dos-meus-funcionários, declarasse frio: os senhores estão despedidos. (ABREU, 2005, p. 140)

Nesse conto, a firma pode ser tomada como uma alegoria para se pensar a estrutura social, que se define como culturalmente masculinizada, atendendo aos propósitos do patriarcado. Aliás, a empresa onde Raul e Saul trabalham é chefiada por um homem, um patriarca, que dita e observa as regras de conduta e de comportamento. No texto, o prédio onde a firma funciona é adjetivado como "feio" e "parecendo uma prisão ou uma clínica psiquiátrica" (Ibid., p. 135). A sociedade onde os protagonistas vivem apresenta características homólogas a uma prisão ou a uma clínica, uma vez que, nelas, os indivíduos são vigiados e orientados a um comportamento que satisfaça às demandas sociais. A demissão dos dois é a própria exclusão a que a sociedade - representada, aqui, por homens e mulheres que obedecem a normas ditadas por um homem - os submete.

Em "Terça-feira gorda", a exclusão e o preconceito contra os homossexuais culminam na violência física de dois rapazes, que, depois de se conhecerem num salão durante uma festa de carnaval e trocarem, publicamente, algumas carícias, são expulsos pelos demais foliões. Mesmo refugiando-se numa praia, sozinhos, são perseguidos e agredidos:

Mas vieram vindo, então, e eram muitos. Foge, gritei, estendendo o braço. Minha mão agarrou um espaço novo. $\mathrm{O}$ pontapé nas costas fez com que me levantasse. Ele ficou no chão. Estavam todos em volta. Olhando para baixo, vi os olhos dele muito abertos e sem nenhuma culpa entre as outras caras dos homens. A boca molhada afundando no meio duma massa escura, o brilho de um dente caído na areia. Quis tomá-lo pela mão, protegê-lo com meu corpo, mas sem querer estava sozinho e nu correndo pela areia molhada, os outros todos em volta, muito próximos. Fechando os olhos então, como um filme contra as pálpebras, eu conseguia ver três imagens se sobrepondo. Primeiro o corpo suado dele,

Revista Eletrônica Literatura e Autoritarismo: Narrativa Testemunhal e Relações Históricas - ISSN 1679-849X |13| http://cascavel.ufsm.br/revistas/ojs-2.2.2/index.php/LA/index 
sambando, vindo em minha direção. Depois as Plêiades, feito uma raquete de tênis suspensa no céu lá em cima. $E$ finalmente a queda lenta de um figo muito maduro, até esborrachar-se contra o chão em mil pedaços sangrentos. (lbid., p. 59)

A exclusão, o preconceito e a violência são explícitos nessa passagem do conto. Convém, ainda, atentar para o seu título. A terça-feira gorda é o último dia do carnaval e antecede a quarta-feira de cinzas. O sentimento social é, pois, de aproveitar ao máximo esse último dia. No texto, a alegria está na própria festa, mas também na celebração alegre e coletiva da morte. O carnaval, nessas chaves, serviria para camuflar o que há de violência e de desrespeito no tecido cotidiano das relações humanas. A violência contra os protagonistas, considerando-se que se deu durante as festas carnavalescas, se traduz numa brincadeira a mais, algo que implica a pouca importância ou 0 pouco valor atribuído aos homossexuais. Eles são vistos como subcategorias, reduzidos à condição de objetos de bizarria e/ou de ridicularização. O excerto alude também à falta de espaço e de liberdade dada aos grupos homossexuais na sociedade contemporânea.

Como se verifica, as elites dominantes criam arcabouços de excluídos para justificar a inconsistência de seus atos. Como afirma João Silvério Trevisan (2007, p. 22), “a civilização sempre precisou de reservatórios negativos que possam funcionar como bodes expiatórios nos momentos de crise e mal-estar", ou seja, frente a situações sem saída a que se encontra o poder, o que resta é atacar o outro. Nesses casos, as ideologias preconceituosas disseminadas justificam a criminalização, a violência e a exclusão social, tornando-as legítimas e aceitáveis. Resguardadas as proporções, o Brasil assimilou práticas de exclusão a exemplo do que se verificou na Europa nazista.

Tais afirmações podem ser observadas no conto "Ah, esses Jovens Brancos de Terno e Gravata!", publicado no livro Negros em contos (1996), de Luiz Silva. No texto, a discriminação racial é apresentada em primeira pessoa pela voz da própria vítima. Depois de descer a Rua da Independência e dirigir-se ao Banco Suor do Povo para saldar uma dívida, o protagonista engrossa uma fila de pessoas que, assim como ele, desejam pagar as suas 
contas. À sua frente, está "um casalzinho conversando" (SILVA, 1996, p. 101). O narrador os descreve como um executivo de terno e gravata e uma moça mais pobre, vestindo calça de brim e camiseta. Impaciente, o branco reclama: "O Brasil não vai pra frente por causa desses preto e desses baiano. Essa gente é que é o nosso atraso. O governo devia acabar com tudo eles..." (lbid., 101).

Nessa passagem, nota-se que não há razões convincentes e plausíveis para o rapaz ter feito tal constatação. A fila estava demorada e, nela, presumivelmente, havia todos os tipos de pessoas, dentre elas, negros e baianos. Foi isso que levou o rapaz a fazer tal declaração. Esta, entretanto, não é a causa determinante, porque ele - homem, branco, executivo, supostamente "culto" - também estava na mesma fila. Disso se conclui que o preconceito é a manifestação de um sentimento naturalizado e, acima de tudo, é "uma crença, e, como tal, profundamente enraizado nos domínios das emoções humanas” (PEREIRA; FERNANDES; NOGUEIRA, 2005-6, p. 177). Além disso, na esteira de um intelectual preconceituoso como Oliveira Vianna, observa-se que o branqueamento social ou o extermínio sistemático consistiriam em estratégias consideradas por ele ponderáveis para se solucionarem os problemas brasileiros (VIANNA, 1956).

A reação do protagonista foi de indignação: "Isso é coisa que se diga? E eu sou preto e sou baiano! Tenho vinte anos de São Paulo, mas sou baiano, oxente!", mas ele fica mesmo irritado quando escuta o seguinte: "Se eu fosse o governo, fazia com esses preto e esses baiano o que Hitler fez com judeu" (SILVA, 1996, p. 102). O extermínio e a violência arbitrária são exercidos em sujeitos que constituem o outro da razão, aqueles que são indiferentes à legitimidade do Estado. O assassinato em massa dos judeus em campos de concentração ocorreu durante a Segunda Guerra Mundial. O gesto de frieza que levou Hitler a cometer esse ato bárbaro transparece naqueles indivíduos que se revestem com a capa de poder ostentada pelo Estado. O jovem executivo alegoriza as instituições macropolíticas, mas a sua atitude na fila do banco sinaliza também as microdimensões do poder, "as microcenas onde ocorrem as interações concretas entre as pessoas na sociedade" (PINHEIRO, 1991, p. 45). Isso significa que o macropoder dialoga 
com o micropoder, formando uma rede de violência que descaracteriza a democracia.

O conto termina com a revolta do protagonista, mas também com sua repressão:

Aí meu sangue freveu! Bati no ombro do cabra. Quando ele virou, eu escarrei na cara dele!!!...

Mas, Seu delegado, eu lhe juro, não fiz mais nada. Tenho inté testemunha. O cabra morreu foi do coração. (SILVA, 1996, p. 102)

O jovem branco de terno e gravata morreu na fila do banco. Uma possível conclusão disso seria a de que a violência teria se extinguido. Essa possibilidade interpretativa é inconsistente, já que o personagem está relatando ao delegado (outro agente de poder) o que aconteceu consigo. É o próprio narrador quem sofreu uma violência moral, mas nem por isso ficou livre do poder e da repressão. O executivo faleceu, é certo, mas agora surge a figura do delegado como símbolo do Estado que se coloca diante do negro. Portanto, considerando-se essa situação, pode-se afirmar que há diferentes formas por meio das quais a violência se manifesta e, também, há o regime contínuo de abuso de poder no Brasil. Conforme destaca Pinheiro (1991, p. 48):

[d]urante toda República no Brasil, as práticas repressivas dos aparelhos de Estado e das classes dominantes estiveram caracterizadas por um alto nível de ilegalidade, independentemente da vigência ou não das garantias constitucionais. Para os pobres, miseráveis e indigentes que sempre constituíram a maioria da população podemos falar de um ininterrupto regime de exceção paralelo sobrevivendo às formas de regime, autoritário ou constitucional.

O que convém destacar, em todos os casos analisados, é a naturalização com que a violência é praticada, e, junto com ela, manifestações de preconceitos e de exclusão social. Seja pelo fato de personagens pertencerem a uma parcela desprestigiada socialmente, seja pelo fato de eles estarem inclusos numa categoria denominada minorias sexuais ou raciais, representam situações que dizem do autoritarismo infligido 
à sociedade brasileira e da discriminação que grupos específicos enfrentam. Essa questão da banalização da violência, a propósito, ficou muito bem representada por Rubem Fonseca em vários de seus contos. Convém, aqui, referir-se a um deles. Trata-se de "Passeio noturno" (Parte II), publicado em 1975.

O aludido conto de Fonseca é dividido em duas partes, mas é na segunda que se conhece melhor o personagem principal e se tem acesso a detalhes importantes que denunciam a sua frieza e a sua crueldade. Trata-se de um homem culto, casado, pai de dois adolescentes e de classe alta: ostenta uma mansão e um automóvel Porsche. Trata-se, também, de um serial killer, que sente necessidade de todos os dias fazer uma vítima, atropelando-a com seu carro extremamente potente e resistente. Em "Passeio noturno" (Parte II), a vítima é Ângela, que diz ser atriz e ter 20 anos. Depois de se conhecerem na Avenida Atlântica, combinam um jantar para o dia seguinte. Após o jantar, em que ela é humilhada pelo protagonista, é brutalmente assassinada por ele. Novamente, aqui, chama a atenção a frieza com que o assassino descreve os detalhes do seu ato violento:

[Ângela] Foi andando pela calçada, lentamente, fácil demais, e ainda por cima mulher, mas eu tinha que ir logo para casa, já estava ficando tarde. Apaguei as luzes e acelerei o carro. Tinha que bater e passar por cima. Não podia correr o risco de deixá-la viva. Ela sabia muita coisa a meu respeito, era a única pessoa que havia visto o meu rosto, entre todas as outras. E conhecia também o meu carro. Mas qual era o problema? Ninguém havia escapado. Bati em Ângela com o lado esquerdo do para-lama, jogando o seu corpo um pouco adiante, e passei, primeiro com a roda da frente - e senti o som surdo da frágil estrutura do corpo se esmigalhando - e logo atropelei com a roda traseira, um golpe de misericórdia, pois ela já estava liquidada, apenas talvez ainda sentisse um distante resto de dor e perplexidade. (FONSECA, 2004, p. 249)

A cena é descrita em primeira pessoa e, a partir da voz do próprio narrador-protagonista, tem-se acesso a um tipo de violência que gera perplexidade porque é narrada de maneira racional em que o criminoso tem consciência de seus atos e o que assusta também é a sua impunidade. Tal impunidade ganha profundidade se se atentar para o fato de que não há uma

Revista Eletrônica Literatura e Autoritarismo: Narrativa Testemunhal e Relações Históricas - ISSN 1679-849X |17| http://cascavel.ufsm.br/revistas/ojs-2.2.2/index.php/LA/index 
causa aparentemente determinante para o seu gesto, é a própria natureza violenta do ser humano que se manifesta em uma sociedade que permite a vazão dos instintos cruéis do homem.

No Brasil, a violência ganhou proporções fora de controle. Se ela tem sido praticada e aceita historicamente, ela se tornou legítima para justificar a exclusão de grupos que não atendem aos interesses do Estado. Indivíduos que apresentam um perfil que lembra Fabiano, de Vidas secas; mulheres indefesas e vítimas de um sistema patriarcal injusto, a exemplo do que se verificou em "Preciosidade" e "A menor mulher do mundo"; homossexuais, que são agredidos constantemente e sem justa causa, como se constatou em "Terça-feira gorda"; e negros, que são vítimas de discriminação racial, como se averiguou em "Ah, esses Jovens Brancos de Terno e Gravata!", geram situações que tornam legítimas por si só as agressões e as discriminações por eles sofridas.

Afora isso, como se observou na análise do conto "Passeio noturno", trata-se de práticas de violência que são tratadas de maneira naturalizada e sem qualquer tipo de punição. Assim, se a violência tornou-se algo legitimado socialmente e se grupos minoritários constituem repertórios em que ela é exercida livremente, deve-se atentar para um estado de exceção em que uma minoria - pessoas ligadas ao poder, cultas, brancas e heterossexuais justificam sua ideologia autoritária e, por extensão, seus atos violentos. A exemplo do que se constatou na Europa nazista, em que ciganos, homossexuais, judeus, dentre outro, foram conduzidos às câmaras de gás por se constituírem no outro da razão (ADORNO, 1994), a sociedade brasileira também tem formado seu arcabouço de excluídos passíveis de eliminação. Essa violência, mesmo não ocorrendo diariamente no tecido social, está presente como uma ameaça constante que umedece a expressão dos direitos humanos.

Assim, a literatura brasileira tem contribuído para a denúncia de um sistema injusto, violento e autoritário, e o tem feito por meio da representação de grupos marginalizados e discriminados. Cabe à literatura e às artes em geral denunciar esse sistema opressor construído historicamente e, com isso, promover a humanização e o conhecimento. Conhecimento esse que, primeiro, instrui os oprimidos a respeito de sua situação como grupo, situado |18| Revista Eletrônica Literatura e Autoritarismo, № 27 - janeiro a junho de 2016 - ISSN 1679-849X http://cascavel.ufsm.br/revistas/ojs-2.2.2/index.php/LA/index 
dentro de relações específicas de dominação e subordinação; segundo, ilumina como esses oprimidos poderiam desenvolver um discurso livre das distorções de sua própria herança cultural parcialmente mutilada; e, terceiro, visaria a uma decodificação radical da história com uma visão do futuro que não apenas explodisse as reificações da sociedade existente, mas também atingisse aqueles desejos e necessidades que abrigam um anseio por uma sociedade nova e por novas formas de relações sociais.

\section{Referências}

ABREU, Caio Fernando. Morangos mofados. Rio de Janeiro: Agir, 2005.

ADORNO, Theodor. Educação após Auschwitz. In:

Gabriel Cohn (Org.). 2. ed. São Paulo: Ática, 1994. p. 33-45. Sociologia.

ADORNO, Theodor; HORKHEIMER, Max. A indústria cultural: o esclarecimento como mistificação das massas. In: _. Dialética do esclarecimento: fragmentos filosóficos. Trad. Guido Antonio de Almeida. Rio de Janeiro: Jorge Zahar Ed., 1985. p. 99-138.

BENJAMIN, Walter. Crítica da violência, crítica do poder. In:

Documentos de cultura, documentos de barbárie: escritos escolhidos. Sel. e apres. Willi Bolle. Trad. Celeste H. M. Ribeiro de Sousa et al. São Paulo: EdUSP, 1986. p. 160-175.

BERG, Creuza. Mecanismos do silêncio: expressões artísticas e censura no regime militar (1964-1984). São Carlos: EdUFSCar, 2002.

FONSECA, Rubem. 64 contos de Rubem Fonseca. São Paulo: Cia das Letras, 2004.

LISPECTOR, Clarice. Laços de família. Rio de Janeiro: Rocco, 1998.

PEREIRA, João Baptista Borges; FERNANDES, Florestan; NOGUEIRA, Oracy. A questão racial brasileira vista por três professores. Revista USP, São Paulo, n. 68. p. 168-179, dez./fev., 2005-6.

PINHEIRO, Paulo Sérgio. Autoritarismo e transição. Revista USP, São Paulo, n. 9, p. 45-56, 1991.

RAMOS, Graciliano. Vidas secas. 29. ed. São Paulo: Martins, 1971.

REIS, Roberto. Cânon. In: JOBIM, José Luís (Org.). Palavras da crítica: tendências e conceitos no estudo da literatura. Rio de Janeiro: Imago, 1992. p. 65-92. 
SAFFIOTI, Heleieth. Gênero, patriarcado, violência. São Paulo: Editora Fundação Perseu Abramo, 2004.

SILVA, Luiz. Negros em contos. Belo Horizonte: Mazza Edições, 1996.

TREVISAN, João Silvério. Devassos no paraíso: a homossexualidade no Brasil, da colônia à atualidade. 7. ed. rev. e ampl. Rio de Janeiro: Record, 2007.

VIANNA, Oliveira. Evolução do povo brasileiro. Rio de Janeiro: José Olympo, 1956.

ZOLIN, Lucia Osana. Desconstruindo a opressão: a imagem feminina em $A$ república dos sonhos, de Nélida Piñon. Maringa: Eduem, 2003. 